\title{
A Bayesian assessment of the conservation status of humpback whales (Megaptera novaeangliae) in the western South Atlantic Ocean
}

\author{
Alexandre N. Zerbini*,+,\# Eric J. Ward*, Paul G. Kinas^, Márcia H. Engel ${ }^{*}$ and Artur Andriolo**,\# \\ Contacte-mail: alex.zerbini@noaa.gov
}

\begin{abstract}
The population of humpback whales (Megaptera novaeangliae) wintering off the eastern coast of South America is referred to by the International Whaling Commission as 'Breeding Stock A' (BSA). This population was heavily exploited in $20^{\text {th }}$ century modern commercial whaling operations After more than 30 years of protection, its present status remains unknown. A deterministic sex and age-aggregated population dynamics model was used to estimate the pre-exploitation population size $(K)$, the maximum net recruitment rate $\left(r_{\max }\right)$, the maximum depletion level $\left(N_{\min } / K\right)$, and other quantities of interest of BSA. Input data included modern whaling catch series, absolute estimates of abundance, observed growth rates and indices of relative abundance. A Bayesian statistical method was used to calculate probability distributions for the model parameters. Prior distributions were set on $r_{\max }$ - an uninformative (Uniform [0, 0.106]) and an informative (Normal [0.067, 0.04 $\left.{ }^{2}\right]$ ) - and on the population size in $2005-N_{2005}$ (Uniform $\left.[500,22,000]\right)$. A total of 10,000 samples were used to compute the joint posterior distribution of the model parameters using the Sampling-Importance-Resampling algorithm. Sensitivity of model outputs to the priors on $r_{\text {mar }}$, a genetic constraint, data inclusion and catch allocation scenarios was investigated. Medians of the posterior probability distributions of quantities of interest for the base case scenario were: $r_{\max }=0.069(95 \%$ probability intervals $[\mathrm{PI}]=0.013-0.104), K=24,558(95 \% \mathrm{PI}=22,791-31,118), N_{\min } / K=2 \%(\mathrm{PI}=0.31 \%-12.5 \%), N_{2006}$ $K=27.4 \%(\mathrm{PI}=18.3 \%-39.5 \%), N_{2020} / K=61.8 \%(\mathrm{PI}=23.8 \%-88.6 \%)$, and $N_{2040} / K=97.3 \%(\mathrm{PI}=31.6 \%-99.9 \%)$. Despite apparent recovery in the past three decades, the western South Atlantic humpback whale population is still low relative to its pre-exploitation size and requires continued conservation efforts.
\end{abstract}

KEYWORDS: HUMPBACK WHALE; POPULATION ASSESSMENT; BAYESIAN STATISTICS; MODELLING; MANAGEMENT; SOUTH ATLANTIC; ANTARCTIC

\section{INTRODUCTION}

Southern Hemisphere humpback whales (Megaptera novaeangliae) were extensively hunted in both coastal and pelagic areas (Best, 1994; Gambell, 1973; Tønnessen and Johnsen, 1982). Protection against whaling was warranted in the late 1960 s by the International Whaling Commission (IWC), but the species continued to be taken illegally by the Soviet fleet up to 1973 (e.g. Yablokov et al., 1998). It is estimated that nearly 200,000 whales were taken in the Southern Hemisphere after 1900, causing the declines of populations to small fractions of their pre-exploitation levels (Allison, 2006; Findlay, 2001).

In the western South Atlantic Ocean (WSA), humpback whales occur in wintering grounds off the eastern coast of South America $\left(\sim 5-25^{\circ} \mathrm{S}\right)$ from June to December (Andriolo et al., 2006a; 2006b; Martins et al., 2001; Zerbini, 2004) with the majority of the population being concentrated in the Abrolhos Bank (Andriolo et al., 2006a; 2006b). Additional winter records have been reported to the north and to the west of $5^{\circ} \mathrm{S}$ (Furtado-Neto et al., 1998) and near oceanic islands off the coast of Brazil (Lodi, 1994), but it is unclear whether these areas correspond to the typical range of the species. This population is referred to as the 'Breeding Stock A' (BSA) by the IWC (IWC, 1998; 2005). Contemporary data suggest that the summering grounds of this stock are located near the Scotia Sea in the Antarctic
Sector of the Southwest Atlantic Ocean. Individuals monitored with satellite telemetry migrated to feeding grounds in offshore areas to the northeast of South Georgia and to the South Sandwich Islands (Zerbini et al., 2006; 2011), within the IWC Management Area II. In addition, one individual photo-identified in Brazil was re-sighted near Shag Rocks, to the west of South Georgia (Stevick et al., 2006).

The WSA humpback whale population was hunted since the 17 th century. Before the $1900 \mathrm{~s}$, whaling operations were of relatively small scale and occurred mainly in low latitude wintering grounds off Brazil (Ellis, 1969; Lodi, 1992; Smith et al., 2006). The introduction of modern whaling techniques and the expansion of the whaling activities to high-density areas in feeding grounds in the early 1900s increased annual catches to several thousand whales and quickly caused the collapse of this population (Findlay, 2001; Tønnessen and Johnsen, 1982).

Previous assessments conducted in the early 2000s suggested that the WSA humpback whale population was still low relative to its pre-exploitation size (Findlay and Johnston, 2001; Findlay et al., 2000; Johnston and Butterworth, 2004; Johnston et al., 2001; Zerbini, 2004; 2005). Since then, additional data on stock identity and migratory connections (IWC, 2006; Rosenbaum et al., 2006; Stevick et al., 2006; Zerbini et al., 2006; 2011), absolute and relative abundance (Andriolo et al., 2006b; Freitas et al.,

\footnotetext{
* School of Aquatic and Fishery Sciences, University of Washington, Box 355020, Seattle, WA 98195-5020, USA.

${ }^{+}$National Marine Mammal Laboratory, Alaska Fisheries Science Center, NOAA Fisheries, 7600 Sand Point Way NE, Seattle, WA 98115-6349, USA.

\# Projeto Monitoramento de Baleias por Satélite, Instituto Aqualie, R. Edgard Werneck 428/32, Rio de Janeiro, RJ 22763-010, Brazil.

Laboratório de Estatística, Departamento de Matemática, Fundação Universidade Federal do Rio Grande, Rio Grande, RS, Brazil.

Instituto Baleia Jubarte/Humpback Whale Institute, Rua Barão do Rio Branco, 26, Caravelas, BA, Brazil.

** Departamento de Zoologia, Instituto de Ciências Biológicas, Universidade Federal de Juiz de Fora, MG, Brazil.
} 
2004; Martins et al., 2001; Ward et al., 2011; Zerbini et al., 2004), population rate of increase (Ward et al., 2011) and an updated catch series (Allison, 2006) have become available. In this study, a Bayesian assessment of the WSA humpback whale population is provided using a sex and age aggregated population dynamics model. The sensitivity of model outputs to different prior distributions, catch allocation hypotheses and input data is investigated.

\section{METHODS}

\section{The data}

Catch data

Humpback whales were caught in wintering grounds off the eastern coast of South America since the 17th century, but catches were of relatively small scale and records are poorly known (Ellis, 1969; Lodi, 1992; Smith et al., 2006). Therefore, in this study, only whales killed by modern whaling (post-1900) are considered.

For the purpose of allocation of historic catches, the IWC Scientific Committee (IWC SC) defined boundaries for the Southern Hemisphere humpback whale breeding stocks in the wintering (areas to the north of $40^{\circ} \mathrm{S}$ ) and feeding grounds (south of $40^{\circ} \mathrm{S}$ ) (IWC, 1998). Wintering ground catches are allocated to BSA if they were taken south of the Equator, north of $40^{\circ} \mathrm{S}$ and west of $20^{\circ} \mathrm{W}$. These included individuals taken in the 20th century by catcher boats operating from whaling stations in Costinha $\left(\sim 7^{\circ} \mathrm{S}, 35^{\circ} \mathrm{W}\right)$ and Cabo Frio $\left(\sim 23^{\circ} \mathrm{S}, 42^{\circ} \mathrm{W}\right)$, in Brazil (Williamson, 1975), and by a Soviet pelagic fleet in the Abrolhos Bank Area $\left(\sim 18^{\circ} 30^{\prime} \mathrm{S}, 38^{\circ} 30^{\prime} \mathrm{W}\right)$ and in offshore areas $\left(\sim 30-32^{\circ} \mathrm{S}, 33-\right.$ $36^{\circ} \mathrm{W}$ ) along the central South American coast (e.g. Allison, 2006; Zemsky et al., 1996).

Feeding ground catches were more difficult to assign to breeding stocks because wintering-feeding ground connections were not yet clear and because mixing may occur in the Southern Ocean. Therefore, the IWC SC developed alternative catch allocation hypotheses (named 'Naïve', 'Fringe' and 'Overlap') to account for possible uncertainties in the feeding ground boundaries (IWC, 1998). These boundaries were subsequently reviewed for some stocks (BSA, BSD and BSG) in light of additional information on migratory connections between low and high latitudes and the former Naïve hypothesis was modified and named 'Core' (IWC, 2011). In this study, catch allocation followed the proposed hypotheses described in Table 1 and illustrated in Fig. 1. Catches included whales taken

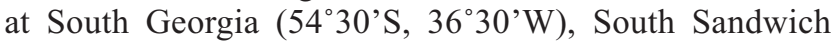
Islands $\left(56^{\circ} 20-59^{\circ} 40^{\prime} \mathrm{S}, 21^{\circ} 30^{\prime} \mathrm{W}\right)$, South Orkney Islands $\left(60^{\circ} 35^{\prime} \mathrm{S}, 45^{\circ} 30^{\prime} \mathrm{W}\right)$, Falkland Islands (59 $\left.30^{\circ} \mathrm{S}, 51^{\circ} 45^{\prime} \mathrm{W}\right)$, the Antarctic Peninsula $\left(\sim 65^{\circ} \mathrm{S}, 60^{\circ} \mathrm{W}\right.$ for the Overlap model only), and pelagic operations in Antarctic waters (Allison, 2006). Sensitivity of catch allocation hypotheses to model parameter estimates was investigated (see below).

\section{Abundance and trend data}

Multiple estimates of abundance were computed for WSA humpback whales. Mark-recapture estimates were obtained only in the wintering grounds (Freitas et al., 2004; Kinas and Bethlem, 1998). Because these estimates corresponded to only a portion of the wintering grounds, they should not be assumed to represent total stock size. Their use as indices of relative abundance was proposed in a preliminary assessment of the BSA (Zerbini, 2004), but the estimated trend obtained from these data (Freitas et al., 2004) was considered unreliable (IWC, 2005). For this reason, mark-recapture-based estimates of population size are not considered further in this study.

Line transect surveys have been conducted in both wintering (Andriolo et al., 2006a; 2006b; Zerbini et al., 2004) and feeding grounds (Branch, 2011; Branch and Butterworth, 2001). Wintering ground estimates were obtained from ship surveys conducted in 1999 and 2000 off the northeastern coast of Brazil $\left(5-12^{\circ} \mathrm{S}\right)$ (Zerbini et al., 2004) and from aerial surveys conducted during 2001 to 2005 (Andriolo et al., 2006a; 2006b). Only the most recent estimate (year 2005), derived from the aerial surveys off Brazil $\left(N_{2005}=6,251\right.$, $\mathrm{CV}=0.17$ ) (Andriolo et al., 2006b), covered the entire stock range and therefore is considered the most current and reliable estimate of the size of BSA (IWC, 2011). This figure is therefore assumed to represent an estimate of absolute abundance when fitting the population dynamics model. Estimates from aerial surveys conducted from 2002 to 2004 (Table 2) were obtained using comparable methodology and covered the same portion of the range of the stock $\left(12-21^{\circ} \mathrm{S}\right)$ in the wintering grounds during the same season (Andriolo et al., 2011). These estimates were therefore used here as an index of relative abundance (hereafter called the 'wintering ground index of abundance', WGIA).

Estimates in the feeding grounds associated to BSA were obtained as part of the IWC International Decade of Cetacean Research/Southern Ocean Whale and Ecosystem Research (IDCR/SOWER) circumpolar program (CP), usually south of $60^{\circ} \mathrm{S}$ in the Antarctic Ocean (Branch, 2011; Branch and Butterworth, 2001). Because there is evidence that a large component of the population remains north of $60^{\circ} \mathrm{S}$ (Reilly et al., 2004; Zerbini et al., 2006) the numbers provided by these surveys should not be used as estimates of total stock size. In this study estimates of abundance from CP surveys of the IDCR/SOWER computed for comparable areas in the feeding grounds linked to BSA $\left(50^{\circ} \mathrm{W}-20^{\circ} \mathrm{W}\right.$, south of $60^{\circ} \mathrm{S}$ ) (Table 2 ; Branch, 2011) were assumed to correspond to another index of abundance (the 'feeding ground index of abundance', FGIA).

Sighting and effort data were collected in the Abrolhos Bank from 1992 to 1998 to investigate the distribution and habitat use of whales off Brazil. Systematic surveys, using comparable methodology, were only conducted from 1995 to 1998 (Martins et al., 2001). Data for this four year period were used to estimate the growth rate of the humpback whale population wintering in the Abrolhos Bank by Ward et al. (2011). The estimate from their best model $(=7.4 \% /$ year, SD

Table 1

Summary of allocation of catches in the feeding ground (south of $40^{\circ} \mathrm{S}$ ) as specified in IWC (1998, 2006a, 2006b) and Allison (2006)

\begin{tabular}{|c|c|c|c|}
\hline Core hypothesis & Falkland catches & Fringe hypothesis & Overlap hypothesis \\
\hline $\begin{array}{l}\text { Catches between } 70-20^{\circ} \mathrm{W} \text { of } \\
\text { longitude and } 40-50^{\circ} \mathrm{S} \text { of latitude, } \\
\text { plus catches from } 50-20^{\circ} \mathrm{W} \text { to the } \\
\text { south of } 50^{\circ} \mathrm{S} \text {, excluding the } \\
\text { Falkland catches }\end{array}$ & $\begin{array}{c}\text { Core catches plus catches } \\
\text { taken from } 70-50^{\circ} \mathrm{W} \text { between } \\
50 \text { and } 58^{\circ} \mathrm{S}\end{array}$ & $\begin{array}{l}90 \% \text { of the catches from the Core } \\
\text { allocation hypothesis and } 10 \% \\
\text { from a 'Fringe Area' between } \\
20 \text { and } 10^{\circ} \mathrm{W}\end{array}$ & $\begin{array}{c}80 \% \text { from Core and } 10 \% \text { from ) } \\
20^{\circ} \mathrm{W}-10^{\circ} \mathrm{E} \text { (the Naïve allocation } \\
\text { hypothesis for BSB) and } 10 \% \text { from } \\
100-50^{\circ} \mathrm{W} \text { (the Core allocation } \\
\text { hypothesis for BSG) }\end{array}$ \\
\hline
\end{tabular}




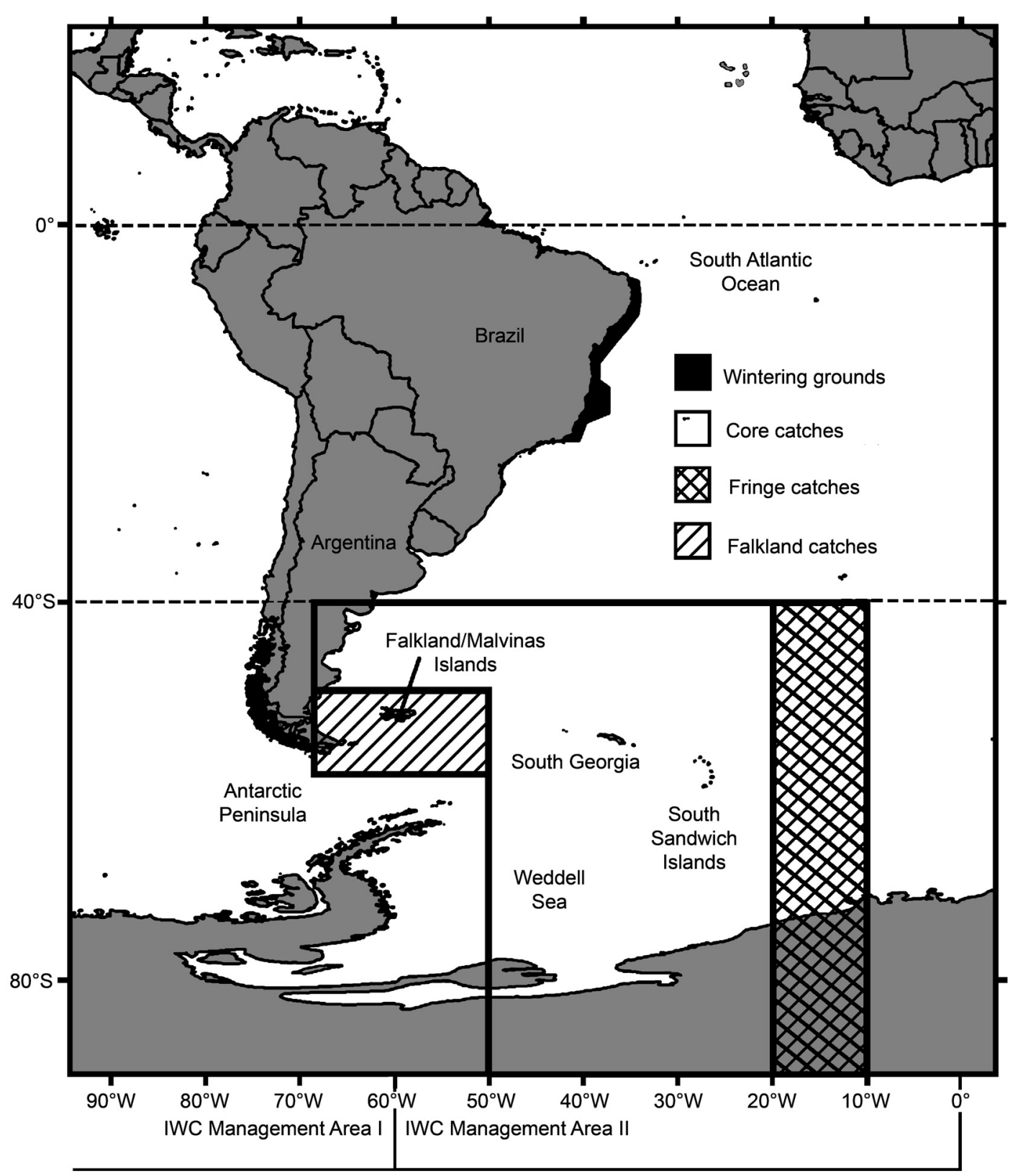

Fig. 1. Breeding stock range in the wintering grounds and feeding ground catch allocation hypotheses.

$=3.3 \%$ ) was used as the 'observed' growth rate when fitting the population dynamics model in this study.

\section{Modelling techniques}

In this study, a Bayesian statistical framework was used to estimate model parameters and quantities of interest (e.g. Gelman et al., 1995; Punt and Hilborn, 1997). Methods were similar to those described and applied to assess the status of the population wintering off the western coast of South America (Breeding Stock G) (Johnston et al., 2011).

\section{Population dynamics model}

The density dependent, sex and age-aggregated generalised logistic equation (e.g. Pella and Tomlinson, 1969) was used to model the dynamics of the humpback whale population. The model is deterministic and is represented as:

$$
N_{t+1}=N_{t}+N_{t} \cdot r_{\max } \cdot\left[1-\left(\frac{N_{t}}{K}\right)^{z}\right]-C_{t}
$$

where:

$N$ is the population size, in numbers, at time ' $t$ ' or ' $t+1$ ', in years;

$r_{\max }$ is the maximum net recruitment rate;

$K$ is the pre-exploitation population size;

$z$ is the parameter that determines the population size where productivity is maximum (also known as shape parameter). This is set here at a value of 2.39 , which corresponds to a maximum sustainable yield level of $0.6 K$ (e.g. Butterworth and Best, 1994; Punt and Butterworth, 1999), as conventionally assumed by the IWC SC.

$C_{t}$ is the harvest, in numbers, in year ' $t$ '.

\section{Estimation of the predicted growth rate}

A predicted growth rate ( $r_{1995-1998)}^{\text {pred }}$ was computed for comparison with the 'observed' growth rate provided by Ward et al. (2011) using the model predicted abundances 
Table 2

Indices of relative abundance in the feeding and breeding grounds of western South Atlantic humpback whales (from Andriolo et al., 2006b and Branch, 2008)

\begin{tabular}{ccccccccc}
\hline \multicolumn{3}{c}{$\begin{array}{c}\text { Feeding ground index of } \\
\text { abundance (FGIA) }\end{array}$} & & & \multicolumn{2}{c}{$\begin{array}{c}\text { Wintering ground index of } \\
\text { abundance (WGIA) }\end{array}$} \\
\cline { 1 - 1 } Year & Cruise & N & & CV & & Year & N & CV \\
\hline $1981 / 82$ & CPI & 45 & 0.91 & & 2002 & 2,305 & 0.20 \\
$1986 / 87$ & CPII & 259 & 0.59 & & 2003 & 2,539 & 0.19 \\
$1997 / 98$ & CPIII & 200 & 0.64 & & 2004 & 3,615 & 0.19 \\
\hline
\end{tabular}

over the period 1995-1998. The predicted rate assumed an exponential growth and was calculated as:

$$
r_{\text {pred }}=\frac{\sum_{t=1995}^{1997} \ln \left(\frac{N_{t+1}^{\text {pred }}}{N_{t}^{\text {pred }}}\right)}{3}=\frac{\ln \left(N_{1998}^{\text {pred }}\right)-\ln \left(N_{1995}^{\text {pred }}\right)}{3}
$$

where:

$N^{\text {pred }}$ is the model predicted population size, in numbers, at time ' $t$ ' or ' $t+1$ ', in years.

\section{Estimation of scaling parameters}

The feeding (FGIA) and wintering ground (WGIA) indices of abundance were scaled to the model predicted population size in year $i$ by the scale coefficient ' $q$ ', assuming a lognormal distribution for their residuals. A separate $q$ was estimated for each index of abundance under the assumption that the same proportion of whales is assumed to occupy the survey areas during the survey period. To consider all forms of uncertainty, we initially allowed each $q$ to be a free parameter in our Bayesian models; this approach proved unsuccessful, however, due to the small sample size for each index $(n=3)$, and high CVs of the FGIA estimates (0.590.91 ), which proved not informative with respect to $q$. As an alternative approach, we treated each $q$ as a nuisance parameter, and estimated them analytically according to equation (3) below for each index of abundance $j$.

$$
\left.q_{j}=e^{\left(\frac{\sum_{i=1}^{n} \frac{\ln \left(\frac{I A_{i j}^{o b s}}{N_{i}^{p r e d}}\right)}{\sigma^{2}}}{\sum_{i=1}^{n} \frac{1}{\sigma_{i j}^{o b s}}}{ }^{\frac{1}{A_{i j}^{o b s}}}\right.}\right)
$$

where:

$I A_{i j}^{o b s}$ is the observed index of abundance $j$ (FGIA or WGIA) in year $i$;

$N_{i}^{\text {pred }}$ is the model predicted population size in year $i$;

$n$ is the number of data points for each index of abundance;

$\sigma_{I A_{i j}^{o b s}}=\sqrt{\ln \left(1+C V_{I A_{i j}^{o b s}}^{2}\right)}$, where CV is the coefficient of variation of the estimated index of abundance $j$ for year $i$.

The analytical solution above corresponds to an approximate Bayesian procedure that involves a reduction in the number of parameters over which to integrate (and therefore a reduction in computational time) by replacing the numerical integration of $q_{j}$ by their maximum likelihood estimates. It has been shown that this approach does not differ from the strictly Bayesian procedure if the prior on $q$ is uniform on a logarithmic scale (Punt and Butterworth, 1996; Walters and Ludwig, 1994).

\section{Statistical framework}

A Bayesian analysis involves integrating the product of prior distributions of parameters and the likelihood functions that links the probability of the observed data to the model predicted parameters. In this study, the generalised logistic model is fit to as many as four sources of data: the absolute abundance estimate $\left(N_{2005}\right)$, the observed growth rate over the period 1995-1998 ( $\left.r_{1995-1998}^{\text {obs }}\right)$, and two indices of abundance (FGIA and WGIA). We used data from additional surveys (1994-1998) to develop an informative prior for the growth rate. The rationale for using an informative prior based on external data is that when a uniform prior is placed on $r_{\max }$, the output is generally non informative because parameters $r_{\max }$ and $K$ are highly correlated in the logistic model (e.g. high values of $K$ and low values or $r_{\max }$ may be equally likely to low values of $K$ and high values of $r_{\max }$ ).

\section{Likelihood functions}

The error distribution of the total stock size and the indices of relative abundance were assumed to be log-normally distributed. The negative of the logarithm of the likelihood the absolute stock size $\left(N_{2005}\right)$ is:

$$
\begin{gathered}
-\ln (L)=\ln \left(\sigma_{N_{2005}}\right)+\ln \left(N_{2005}\right) \\
+0.5 \cdot \frac{\left(\ln \left(N_{2005}^{\text {pred }}\right)-\ln \left(N_{2005}\right)\right)^{2}}{\sigma_{N_{2005}}^{2}}
\end{gathered}
$$

where:

$N_{2005}^{\text {pred }}$ is the model predicted abundance in 2005

$N_{2005}$ is the observed abundance in 2005

$$
\sigma_{N_{2005}}=\sqrt{\ln \left(1+C V_{N_{2005}^{2}}^{2}\right)}
$$

The negative of the logarithm of the likelihood of the indices of abundance is given by:

$$
-\ln (L)=\sum_{i=1}^{n} \sum_{j=1}^{m}\left[\begin{array}{l}
\ln \left(\sigma_{I A_{i j}^{o b s}}\right)+\ln \left(I A_{i j}^{o b s}\right) \\
+0.5 \cdot \frac{\left(\ln \left(q_{j} \cdot N_{i}^{\text {pred }}\right)-\ln \left(I A_{i j}^{o b s}\right)\right)^{2}}{\sigma_{I A_{i j}^{o b s}}^{2}}
\end{array}\right]
$$

where:

$N_{i}^{\text {pred }}$ is the model predicted abundance in year $i$;

$I A_{i j}^{o b s}$ is the observed index of abundance $j$ in year $i$;

$q_{j}$ is the estimated scale parameter for index of abundance $j$;

$\sigma_{I A_{i j}^{\text {ols }}}=\sqrt{\ln \left(1+C V_{L A^{+*}}^{2}\right)}$

The error of the growth rate estimates is assumed to be normally distributed. The negative of the logarithm of the likelihood of the growth rate is given by: 


$$
-\ln (L)=\ln \left(\sigma_{r_{1995-1998}^{o b s}}\right)+0.5 \cdot\left(\frac{r_{1995-1998}^{\text {pred }}-r_{1995-1998}^{o b s}}{\sigma_{r_{1995-1998}^{o b s}}}\right)^{2}
$$

where:

$r_{1995-1998}^{\text {pred }}$ is the model predicted growth rate between 19951998 (from equation 2);

$r_{1995-1998}^{o b s}=7.4 \% /$ year (from Ward et al., 2011);

$\sigma_{r_{190 s} \text { sogs }}=3.3 \%$ year (from Ward et al., 2011).

Thus, the total negative logarithm of the likelihood is the sum of equations (4), (5) and (6), where (5) $=0$ and (6) $=0$ when the indices of abundance and the observed growth rate, respectively, are not present in the model.

The integration of the prior distributions of the parameters and the likelihood function was approximated by the Sampling-Importance-Resampling (SIR) algorithm as implemented by McAllister et al. (1994). This implementation is a special case of the SIR algorithm in which the importance function is set to the prior. In SIR, a large number of independent sets of parameters is randomly drawn from the prior distributions, their likelihood is evaluated given the observed data and each set of data is stored in proportion to their likelihood. In the present study, a total of 10,000 samples were obtained with the SIR algorithm to compute the posterior distribution of parameters and quantities of interest.

\section{Priors}

In Bayesian statistical models probability is used as a measure of uncertainty. Within this paradigm, unknown model parameters have probability distributions based on previous knowledge (the priors), which are then updated using the data to derive the posterior distributions, the keystone of Bayesian inference. Priors can be either uninformative or vague, when they carry no substantial knowledge about the parameter of interest, or informative, when they contain relevant information from previous studies. In this study, prior distributions were specified for $r_{\max }$ and $N_{2005}$. There is no need to specify a prior for the preexploitation population size $(K)$ because it is implicit in the combination of the population model, the catch history and the other priors (Butterworth and Punt, 1995).

Two priors were specified for $r_{\text {max }}$ : a uniform prior, and an informative prior. The latter originated from a Bayesian hierarchical meta-analysis of growth rates of eight formerly depleted whale populations (Branch et al., 2004). This prior has a normal distribution with mean 0.067 and standard deviation 0.04. Prior distributions of $r_{\max }$ were bounded. The lower boundary of was set to zero because negative maximum net recruitment rates are biologically implausible and the upper boundary corresponds to the maximum growth rate for the species computed from a range of life history parameters observed for several humpback whale populations (10.6\%/year, Clapham et al., 2006; IWC, 2007a).

The prior distribution on $N_{2005}$ was uniform (U[500, 22000]). The lower and upper bounds were fixed to a value thought to be greater than the greatest possible value in the posterior probability distribution, but small enough to limit computational time (e.g. Wade, 2002). Although the choice of these bounds may seem arbitrary, their values were assessed not to be important, as they do not influence the results.

\section{Population projection}

The population was projected using the 'backwards' method of Butterworth and Punt (1995). The prior distributions of the current absolute abundance $\left(N_{2005}\right)$ and the maximum net recruitment rate $\left(r_{\max }\right)$ are sampled and then used to determine the unique value of the population in 1901 (assumed to correspond to $K$ ) that corresponds to the value drawn from the prior for $N_{2005}$, given $r_{\max }$ and the applied catch series. This process is accomplished by using a bisection method (Butterworth and Punt, 1995). In this study, the population is projected into the future (2006 to 2040) assuming that non-natural mortality has not taken place since whaling for this stock ceased.

\section{Quantities of interest, modelling scenarios and sensitivity analyses}

Posterior probability distributions were calculated for the following parameters and quantities of interest: $r_{\max }, K$, Minimum population size $\left(N_{\min }\right)$, population in $2006\left(N_{2006}\right)$, maximum depletion level $\left(N_{\min } / K\right)$, and depletion levels in $2006\left(N_{2006} / K\right)$, in $2020\left(N_{2020} / K\right)$ and in $2040\left(N_{2040} / K\right)$.

\section{The base case scenario}

The base case scenario (BC) comprises the following prior, data and catch allocation hypothesis:

Prior distribution on $r_{\max }$ : Uniform distribution;

Observed growth rate: $r_{1995-1998}^{o b s}=7.4 \% /$ year $(\mathrm{SD}=3.3 \%)$;

Absolute abundance: $N_{2005}=6251(\mathrm{CV}=0.17)$;

Catch allocation: Core hypothesis.

\section{Sensitivity analyses}

The sensitivity of the $\mathrm{BC}$ to the specification of different prior distributions, to the inclusion of various sets of data and to the different catch allocation hypotheses was investigated. The analyses are divided into four different sets of model runs: Choice of Prior on $r_{\text {max }}$, Genetic Constraint, Data Inclusion and Catch Allocation. A summary of the proposed scenarios is presented in Table 3.

\section{CHOICE OF PRIOR ON $\boldsymbol{R}_{\text {MAX }}$}

The uniform prior presented in the BC was replaced by the informative (Meta-analysis) prior of Branch et al. (2004).

\section{GENETIC CONSTRAINTS}

Jackson et al. (2006) suggested that a genetic constraint be used in the assessment of South Pacific humpback whale populations given the observed genetic diversity. This idea had previously been discussed by Baker and Clapham (2004), who advocated that demographic and genetic approaches should be integrated to better describe whale population dynamics.

The same approach was used here to determine a minimum population size of humpback whales from BSA, given their observed genetic diversity. Baker and Clapham (2004) suggested that the number of extant haplotypes sampled in a population which has undergone a recent bottleneck provides an absolute minimum bound on the number of mature females in the population at the time of the bottleneck (Patenaude, 2002). Jackson et al. (2006) proposed a correction factor of 4 to scale the number of sampled haplotypes (minimum number of mature females) to the total (census) population size when the population was at its minimum. The rationale behind this correction factor is that the number of haplotypes must be multiplied by two 
Table 3

Summary of the Base Case and sensitivity analysis used in the assessment of humpback whales in the western South Atlantic Ocean.

\begin{tabular}{|c|c|c|}
\hline Scenario & Base Case & Baleen whale meta-analysis $r_{\max }$ \\
\hline Prior on $r_{m a x}$ & Uniform $[0.00,0.106]$ & Normal $\left[0.067,0.04^{2}\right]$ \\
\hline Observed growth rate present & Yes & Yes \\
\hline Indices of abundance & - & - \\
\hline Genetic constraint & - & - \\
\hline Catch allocation & Core & Core \\
\hline Scenario & Genetic constraint & FGIA \\
\hline Prior on $r_{\max }$ & Uniform $[0.00,0.106]$ & Uniform $[0.00,0.106]$ \\
\hline Observed growth rate present & Yes & Yes \\
\hline Indices of abundance & - & FGIA \\
\hline Genetic constraint & Minimum population $=264$ & - \\
\hline Catch allocation & Core & Core \\
\hline Scenario & WGIA & FGIA + WGIA \\
\hline Prior on $r_{\max }$ & Uniform $[0.00,0.106]$ & Uniform $[0.00,0.106]$ \\
\hline Observed growth rate present & No & Yes \\
\hline Indices of abundance & - & FGIA + WGIA \\
\hline Genetic constraint & - & - \\
\hline Catch allocation & Core & Core \\
\hline Scenario & No observed growth rate, FGIA + WGIA & Falkland catches \\
\hline Prior on $r_{m a x}$ & Uniform $[0.00,0.106]$ & Uniform $[0.00,0.106]$ \\
\hline Observed growth rate present & No & Yes \\
\hline Indices of abundance & FGIA + WGIA & - \\
\hline Genetic constraint & - & - \\
\hline Catch allocation & Core & Core + Falkland catches \\
\hline Scenario & Fringe catches & Overlap catches \\
\hline Prior on $r_{\max }$ & Uniform $[0.00,0.106]$ & Uniform $[0.00,0.106]$ \\
\hline Observed growth rate present & Yes & Yes \\
\hline Indices of abundance & - & - \\
\hline Genetic constraint & - & - \\
\hline Catch allocation & Fringe catches & Overlap catches \\
\hline
\end{tabular}

to account for the male population (assuming an even sex ratio) and also by two to correct the minimum effective population size to a lower estimate of census population size (Nunney, 1993; Roman and Palumbi, 2003). Jackson et al. (2006) pointed out that this correction factor is conservative, but useful to provide a minimum census population number. Including this constraint in our models can be seen as part of the prior (bounds are commonly used in priors on positive quantities, such as variance parameters), and not additional data.

The total number of mtDNA haplotypes found in whales from BSA was estimated at 66 (Rosenbaum et al., 2006), resulting in a minimum population of 264 whales. Therefore, all population trajectories resulting in a minimum abundance lower than 264 individuals were penalised by having their likelihood set to zero.

\section{DATA INCLUSION}

A total of four scenarios were proposed to investigate the sensitivity of the $\mathrm{BC}$ to the inclusion/removal of different data in the fit of the model (Table 3). The objective of scenarios FGIA, WGIA and FGIA + WGIA in Table 3 was to investigate whether the inclusion of the indices of relative abundance (FGIA, WGIA, or both) provided additional trend information and how these input data influenced the model outputs. In the fourth scenario ("no observed growth rate, FGIA + WGIA' in Table 3), the observed growth rate was removed from the model fit (but the indices of abundance, FGIA and WGIA, were retained) in order to assess how informative this rate was for computation of model outputs.

\section{CATCH ALLOCATION}

The sensitivity of the model outputs to the different hypotheses for feeding ground catch allocation was also investigated. The 'Fringe' and 'Overlap' catch allocations were compared to the 'Core' hypothesis used in the Base Case. In addition, because it is not clear whether individuals taken in the Falkland Islands $\left(59^{\circ} 30^{\prime} \mathrm{S}, 51^{\circ} 45^{\prime} \mathrm{W}\right)$ belonged to BSA, the present assessment investigates the sensitivity of their inclusion in the analyses. The catch series used in the proposed scenarios were provided by Allison (2006) and are presented in Table 4.

\section{RESULTS}

Posterior distribution of model parameters for all scenarios investigated in this study (Table 5) were obtained from 10,000 unique parameter vectors of the SIR algorithm.

\section{Base case}

The posterior distribution of the parameters and quantities of interest for the BC scenario are presented in Table 5 and illustrated in Fig. 2. The point estimate (median of the posterior probability distribution) on $r_{\text {max }}$ is $0.069(95 \%$ probability interval $[\mathrm{PI}]=0.013-0.104$, Fig. $2 \mathrm{~A})$. The 
Table 4

Catch series for the allocation scenarios used in the assessment of western South Atlantic humpback whales (from Allison, 2006).

\begin{tabular}{|c|c|c|c|c|c|c|c|c|c|}
\hline Year & $\begin{array}{l}\text { Core } \\
\text { catches }\end{array}$ & $\begin{array}{c}\text { Falkland } \\
\text { catches }\end{array}$ & $\begin{array}{l}\text { Fringe } \\
\text { catches }^{1}\end{array}$ & $\begin{array}{l}\text { Overlap } \\
\text { catches }\end{array}$ & Year & $\begin{array}{c}\text { Core } \\
\text { catches }\end{array}$ & $\begin{array}{c}\text { Falkland } \\
\text { catches }\end{array}$ & $\begin{array}{l}\text { Fringe } \\
\text { catches }^{1}\end{array}$ & $\begin{array}{l}\text { Overlap } \\
\text { catches }\end{array}$ \\
\hline 1904 & 180 & 0 & 180 & 144 & 1939 & 2 & 0 & 2 & 2 \\
\hline 1906 & 240 & 0 & 240 & 242 & 1941 & 13 & 0 & 13 & 10 \\
\hline 1907 & 1,261 & 0 & 1,261 & 1,045 & 1942 & 0 & 0 & 0 & 0 \\
\hline 1908 & 1,849 & 6 & 1,849 & 1,605 & 1943 & 4 & 0 & 4 & 3 \\
\hline 1909 & 3,391 & 66 & 3,391 & 2,870 & 1944 & 60 & 0 & 60 & 48 \\
\hline 1911 & 5,832 & 12 & 5,832 & 4,892 & 1946 & 30 & 0 & 31 & 24 \\
\hline 1912 & 2,881 & 6 & 2,881 & 2,472 & 1947 & 35 & 0 & 36 & 30 \\
\hline 1913 & 999 & 5 & 999 & 974 & 1948 & 48 & 0 & 67 & 51 \\
\hline 1914 & 1,155 & 8 & 1,155 & 1,054 & 1949 & 83 & 0 & 212 & 116 \\
\hline 1915 & 1,697 & 0 & 1,697 & 1,396 & 1950 & 698 & 0 & 712 & 614 \\
\hline 1916 & 447 & 0 & 447 & 373 & 1951 & 45 & 0 & 102.5 & 84 \\
\hline 1917 & 121 & 0 & 121 & 116 & 1952 & 34 & 0 & 50.5 & 49 \\
\hline 1918 & 129 & 0 & 129 & 124 & 1953 & 140 & 0 & 155.5 & 124 \\
\hline 1920 & 102 & 0 & 102 & 97 & 1955 & 96 & 0 & 137.5 & 94 \\
\hline 1921 & 9 & 0 & 9 & 7 & 1956 & 167 & 0 & 199.5 & 210 \\
\hline 1922 & 364 & 0 & 364 & 310 & 1957 & 61 & 2 & 77.5 & 61 \\
\hline 1923 & 133 & 0 & 133 & 116 & 1958 & 16 & 0 & 19 & 28 \\
\hline 1924 & 266 & 0 & 266 & 223 & 1959 & 15 & 36 & 18.5 & 40 \\
\hline 1925 & 254 & 0 & 254 & 220 & 1960 & 27 & 0 & 29 & 45 \\
\hline 1926 & 7 & 0 & 7 & 16 & 1961 & 13 & 4 & 13 & 132 \\
\hline 1927 & 0 & 1 & 0 & 0 & 1962 & 24 & 1 & 26 & 53 \\
\hline 1928 & 19 & 0 & 19 & 17 & 1963 & 12 & 22 & 12 & 12 \\
\hline 1929 & 51 & 0 & 56 & 42 & 1964 & 0 & 0 & 0 & 0 \\
\hline 1930 & 107 & 0 & 120 & 92 & 1965 & 52 & 0 & 69 & 133 \\
\hline 1931 & 18 & 0 & 19 & 15 & 1966 & 0 & 0 & 0 & 15 \\
\hline 1932 & 23 & 0 & 24 & 20 & 1967 & 189 & 0 & 192 & 226 \\
\hline 1933 & 132 & 0 & 151 & 114 & 1968 & 0 & 0 & 0 & 0 \\
\hline 1934 & 57 & 0 & 64 & 49 & 1969 & 0 & 0 & 0 & 0 \\
\hline 1935 & 48 & 0 & 149 & 68 & 1970 & 0 & 0 & 0 & 0 \\
\hline 1936 & 105 & 0 & 149 & 109 & 1971 & 0 & 0 & 0 & 0 \\
\hline
\end{tabular}

${ }^{1}$ Fractional catches occur under the 'Fringe' hypothesis because of proportional allocation of catches between areas (see IWC, 1998).

posterior median of $K$ indicates that the size of the humpback whale population wintering off the western coast of South America was nearly 24,600 individuals (95\% PI $=22,791-$ 31,118 ) before exploitation by modern whaling (Fig. 2B).

The population trajectory (Fig. 3) shows that the population was severely depleted after a period of intense exploitation between 1905 and 1920 and remained low for the following 40 years, a period which it sustained small catches. BSA reached its lowest numbers in the late 1950s, when nearly $500(95 \%$ PI $=159-3,943)$ individuals existed in the population. This number corresponds to a depletion level of nearly $2 \%$ of $K(95 \% \mathrm{PI}=0.7 \%-12.5 \%)$ (Fig. $2 \mathrm{C})$. In the early 1960 s this population started to recover and, despite the several hundred individuals taken by the Soviet whaling, it has continued to grow. The population size in 2006 was estimated to be about 6,800 whales $(95 \%$ PI $=4,902-9,567)$, which corresponds to a depletion level of $27 \%$ of the pre-exploitation population size $(95 \%$ $\mathrm{PI}=18.3-39.5 \%$ ) (Fig. 2D). Assuming no human-induced mortality occurs in the future, it is predicted that BSA will reach $62 \%$ of $K(95 \% \mathrm{PI}=23.8-88.6 \%)$ in 2020 (Fig. 2E) and will be nearly recovered in $2040(95 \% \mathrm{PI}=36.5-99.9 \%)$ (Fig. 2F).

\section{Sensitivity to choice of prior}

Posterior probability distributions for model outputs are presented in Fig. 2. The use of the 'baleen whale metaanalysis' prior had very little effect on the model outputs (Table 5), except that it provided slightly more precise estimates of model parameters. Yet, posterior distributions of model outputs between this and the BC scenario overlapped to a great extent (Fig. 2).

\section{Sensitivity to the genetic constraint}

The addition of a genetic constraint prevented the population trajectory from reaching values lower than 264 individuals. This resulted in a small decrease in the posterior median of $r_{\max }$ (from 0.069 down to 0.062 ) and a small increase in $K$ (from 24,600 to 25,000 ). The posterior median of the minimum populations for this scenario (629 individuals) was greater than the one estimated with the $\mathrm{BC}$ scenario, resulting in a greater maximum depletion level (from $2 \%$ to $2.4 \%$, Table 5). Posterior medians of the status of the population in 2006, 2020 and 2040 were more pessimistic than the BC scenario. Despite these changes, the posterior probability distributions between the genetic constraint and the BC scenario overlapped to a great extent (Fig. 2).

\section{Sensitivity to data inclusion}

The inclusion of the FGIA resulted in a small increase in precision but posterior distributions of model parameters were similar to the BC scenario (Table 5, Fig. 4). In contrast, the addition of the WGIA resulted in an increase in the posterior median of $r_{\max }$ and current status, and consequently, a decrease in $K$ and the maximum depletion level. Figs 5A and $5 \mathrm{~B}$ show the fit of the population dynamics model to each of these indices of abundance. When both FGIA and WGIA were included in the analysis greater precision and 
Table 5

Posterior medians, means and 95\% probability intervals of model parameters estimated for the assessment of western South Atlantic humpback whales.

\begin{tabular}{|c|c|c|c|c|c|c|c|c|}
\hline & \multicolumn{4}{|c|}{ Base case } & \multicolumn{4}{|c|}{ Baleen whale meta-analysis $r_{\max }$ prior } \\
\hline & Median & Mean & $2.5 \%$ & $97.5 \%$ & Median & Mean & $2.5 \%$ & $97.5 \%$ \\
\hline$r_{\max }$ & 0.069 & 0.066 & 0.013 & 0.104 & 0.069 & 0.068 & 0.022 & 0.103 \\
\hline$K^{\max }$ & 24,558 & 25,110 & 22,791 & 31,118 & 24,514 & 24,846 & 22,844 & 28,955 \\
\hline$N_{\text {min }}$ & 503 & 850 & 159 & 3,943 & 490 & 710 & 168 & 2,680 \\
\hline$N_{2006}^{\min }$ & 6,808 & 6,929 & 4,902 & 9,567 & 6,851 & 6,947 & 4,942 & 9,529 \\
\hline Max Depletion & 0.020 & 0.031 & 0.007 & 0.125 & 0.020 & 0.027 & 0.007 & 0.092 \\
\hline Depletion in 2020 & 0.618 & 0.601 & 0.238 & 0.886 & 0.628 & 0.615 & 0.287 & 0.879 \\
\hline \multirow[t]{3}{*}{ Depletion in 2040} & 0.973 & 0.879 & 0.316 & 0.999 & 0.975 & 0.908 & 0.444 & 0.999 \\
\hline & \multicolumn{4}{|c|}{ Genetic constraint } & \multicolumn{4}{|c|}{ FGIA } \\
\hline & Median & Mean & $2.5 \%$ & $97.5 \%$ & Median & Mean & $2.5 \%$ & $97.5 \%$ \\
\hline$r_{\max }$ & 0.062 & 0.059 & 0.011 & 0.092 & 0.068 & 0.066 & 0.017 & 0.103 \\
\hline$N_{\min }$ & 612 & 987 & 278 & 4,222 & 511 & 788 & 163 & 3,351 \\
\hline$N_{2006}^{\min }$ & 6,895 & 6,994 & 4,947 & 9,659 & 6,840 & 6,947 & 4,906 & 9,498 \\
\hline Max Depletion & 0.024 & 0.036 & 0.012 & 0.133 & 0.021 & 0.030 & 0.007 & 0.111 \\
\hline Depletion in 2006 & 0.272 & 0.276 & 0.179 & 0.397 & 0.275 & 0.280 & 0.186 & 0.395 \\
\hline Depletion in 2020 & 0.574 & 0.562 & 0.226 & 0.861 & 0.617 & 0.605 & 0.258 & 0.882 \\
\hline \multirow[t]{3}{*}{ Depletion in 2040} & 0.951 & 0.855 & 0.284 & 0.999 & 0.972 & 0.892 & 0.365 & 0.999 \\
\hline & \multicolumn{4}{|c|}{ WGIA } & \multicolumn{4}{|c|}{ FGIA + WGIA } \\
\hline & Median & Mean & $2.5 \%$ & $97.5 \%$ & Median & Mean & $2.5 \%$ & $97.5 \%$ \\
\hline$r_{\max }$ & 0.075 & 0.071 & 0.020 & 0.104 & 0.074 & 0.071 & 0.023 & 0.104 \\
\hline$K^{\max }$ & 24,229 & 24,670 & 22,786 & 29,348 & 24,274 & 24,655 & 22,796 & 28,817 \\
\hline$N_{\min }$ & 426 & 674 & 153 & 2,887 & 437 & 652 & 158 & 2,622 \\
\hline$N_{2006}^{\min }$ & 6,866 & 6,975 & 4,931 & 9,546 & 6,836 & 6,943 & 4,885 & 9,541 \\
\hline Max Depletion & 0.018 & 0.026 & 0.007 & 0.098 & 0.018 & 0.025 & 0.007 & 0.091 \\
\hline Depletion in 2006 & 0.280 & 0.284 & 0.190 & 0.400 & 0.279 & 0.283 & 0.191 & 0.399 \\
\hline
\end{tabular}

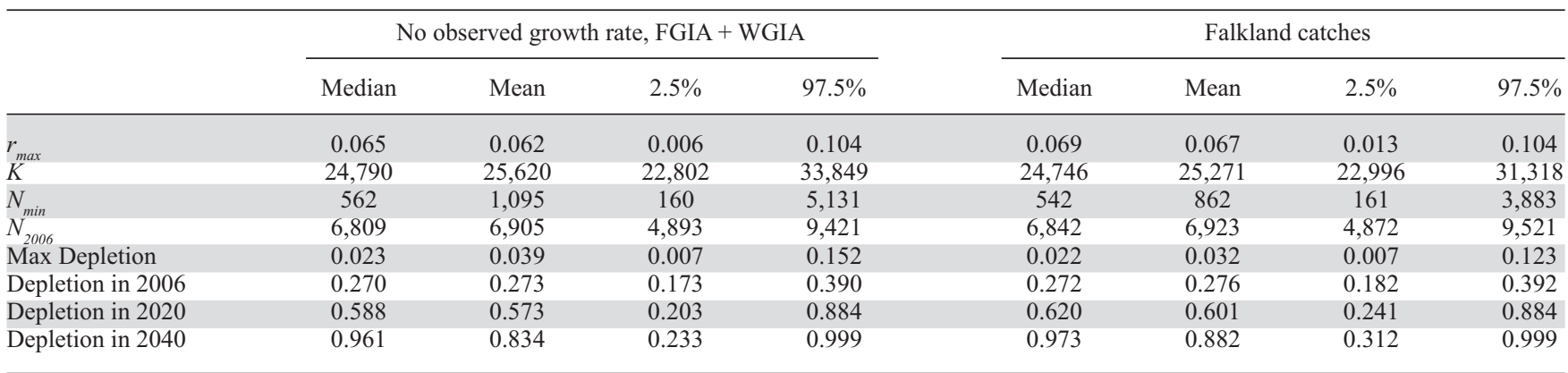

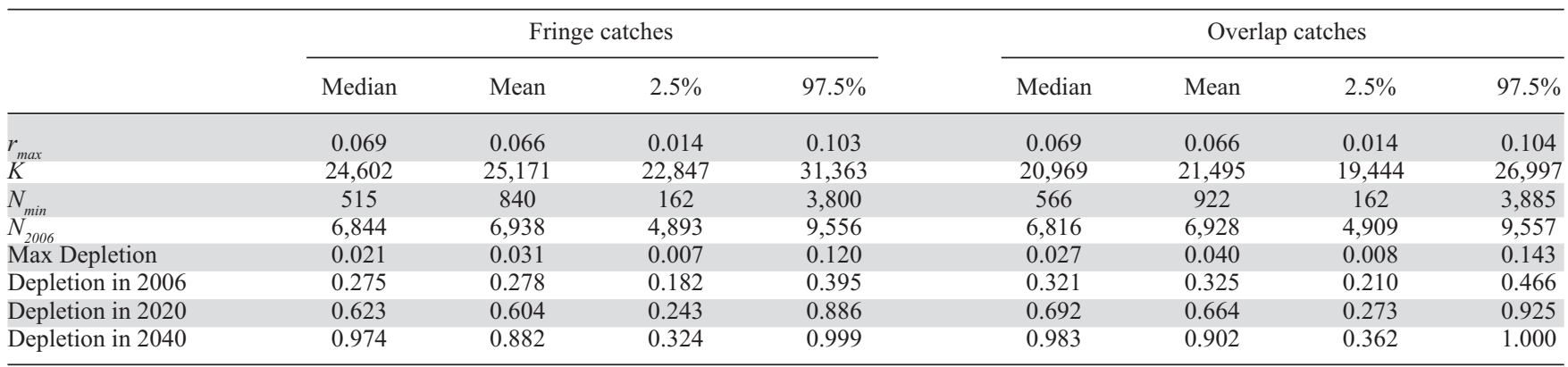

therefore more informative results were obtained. Finally, the removal of the observed growth rate resulted in greater uncertainty in parameter estimates, a slightly lower estimate of $r_{\max }$ and a slightly more pessimistic estimate of current population status (Table 5). Despite all these differences, the posterior probability distributions of all depletion parameters in the data inclusion scenarios were relatively consistent with those obtained in the BC scenario (Fig. 4).
Sensitivity to catch allocation hypothesis

The posterior medians of the model parameters estimated with the Fringe and the Falkland Island catches were similar between the $\mathrm{BC}$ scenario (the Core catches) and the Fringe catches (Table 5, Fig. 6), suggesting almost no difference in results between these catch allocation hypotheses. In contrast, the scenario with the Overlap catch allocation hypothesis produced lower and higher posterior medians of 

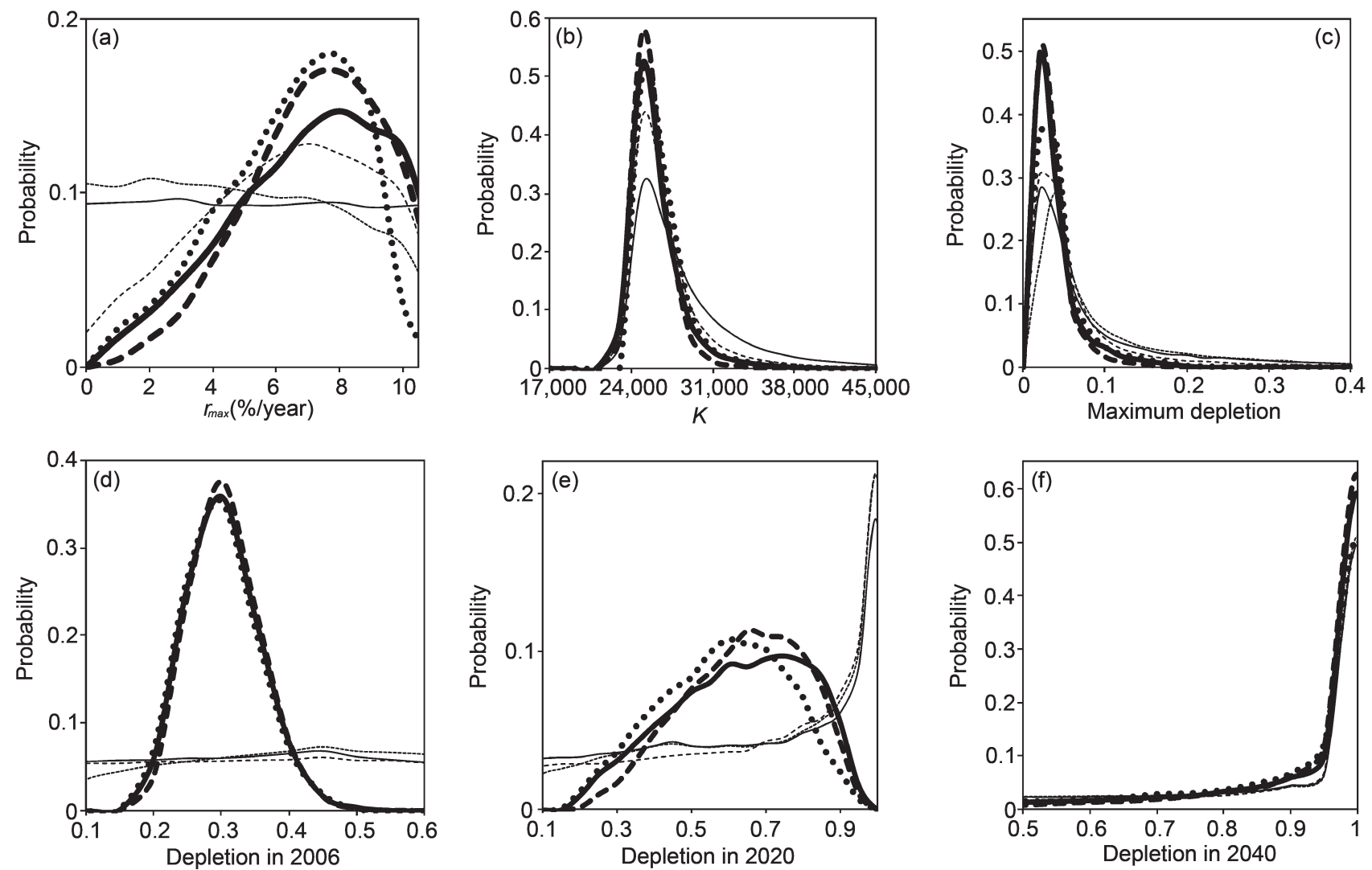

Fig. 2. Posterior (thick lines) and realised prior (thin lines) probability distributions of model parameters and other quantities of interest for the 'Choice of Prior' and 'Genetic Constraint' sensitivity analyses (solid lines = base case; dashed line = baleen whale meta-analysis prior; and dotted line = genetic constraint).

$K$ and of the current (2006) status, respectively. The posterior distribution of $K$ between the Overlap and the other catch allocation hypothesis showed very little overlap (Fig. 6B). Also, the Overlap scenario produced more optimistic projections of the recovery of the WSA humpback whale population (Fig. 6).

\section{DISCUSSION}

In this study, multiple scenarios were presented to assess the status of the humpback whale population wintering off the eastern coast of South America. They include the use of a different prior distribution for the maximum net recruitment rate, model adjustment to different sets of data and catch allocations. While some variation in the model outputs existed depending on the prior/data used, consistency was observed in almost all scenarios.

The use of an informative prior on $r_{\max }$ (the baleen whale on population growth rates hierarchical meta-analysis) (Branch et al., 2004) had very little effect in the model outputs relative to the base case. The posterior median was the same and the posterior distribution was slightly more precise. Gain in precision is a result of the use on a more informative prior relative to the uniform distribution used in the base case, but because the informative prior itself had a relatively low precision $(\mathrm{CV}=0.6)$, the gain is negligible.

Adding a genetic constraint resulted in small changes in the posterior median of the model outputs. The maximum depletion level was greater and the depletion parameters were less optimistic than the BC scenario. The purpose of adding a genetic constraint was to prevent the model from reaching a minimum population size (264 individuals) that was unrealistic given the known genetic diversity of the population. This resulted in eliminating predicted population trajectories with high growth rates as illustrated in Fig. 2 and Table 5, where the posterior median and the upper boundary of $r_{\max }$ are lower than those estimated by the base case. Although lower values of $r$ also resulted in slightly more pessimistic posterior medians of the depletion parameters, their posterior distribution overlapped to a great extent (Fig. 2).

Inclusion of the indices of abundance resulted only in small differences in posterior medians and slightly more precise estimates of model outputs. The main reason for that

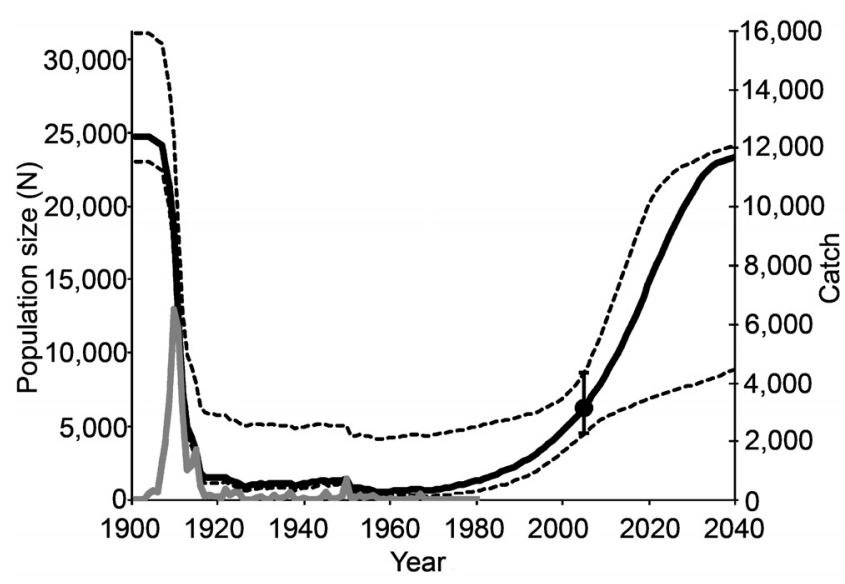

Fig. 3. Population trajectory and fit of the model to the absolute abundance in 2005 of the Base Case scenario. The solid line correspond to the posterior median, dashed lines to the $95 \%$ probability intervals, error bars to the $95 \%$ confidence intervals of the abundance estimate and the grey line to the Core catch series. 

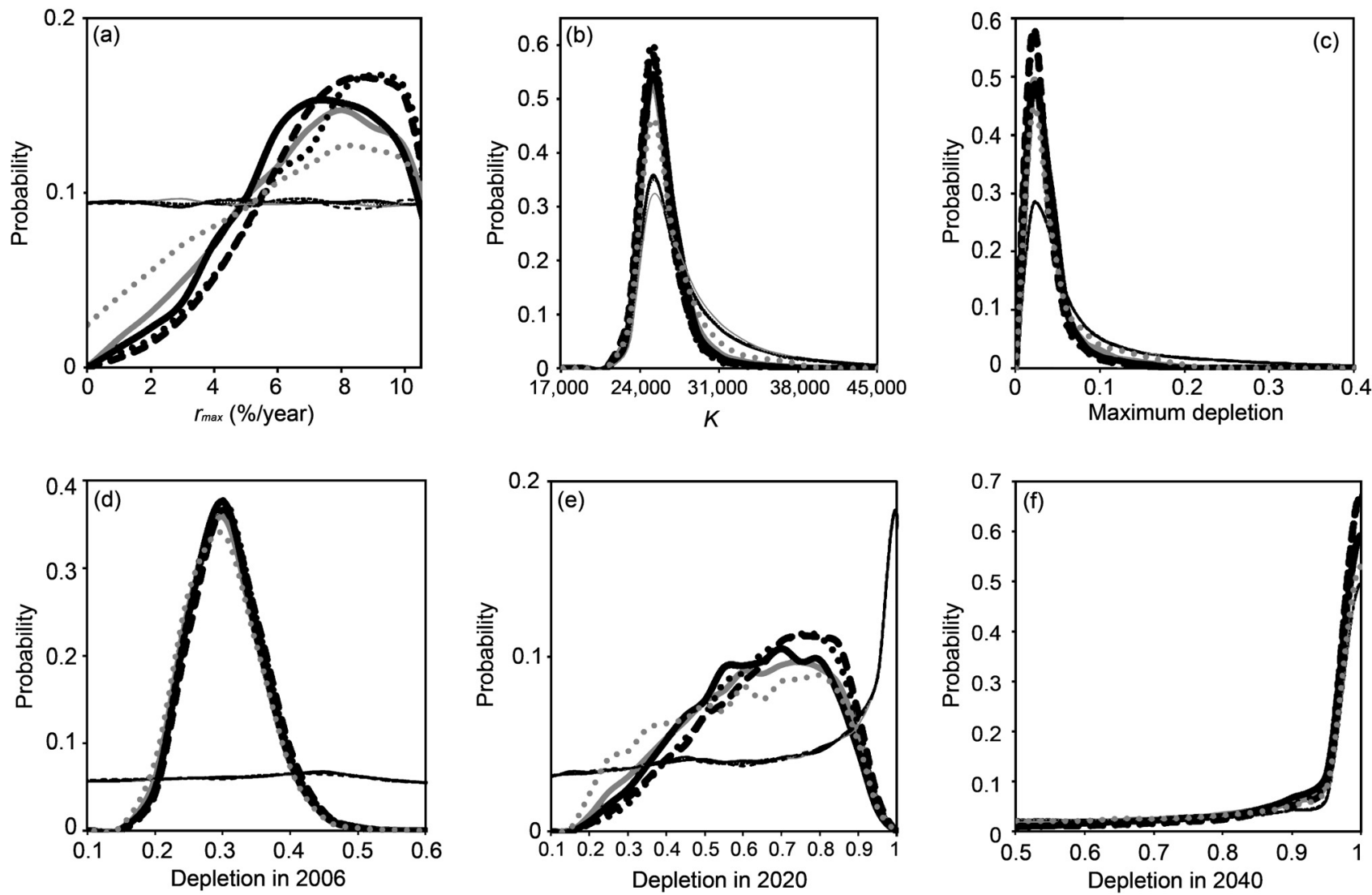

Fig. 4. Posterior (thick lines) and realised prior (thin lines) probability distributions of model parameters and other quantities of interest for the 'Data Inclusion' sensitivity analyses (solid line = FGIA; dashed line = WGIA; and dotted line = FGIA + WGIA). The posterior and prior distributions for the base case scenario are illustrated as a thick gray line for comparison.

is that the indices of abundance used in this study are not very informative. The estimates of abundance from the IDCR/SOWER surveys, despite covering a relatively large period of time (1981/82-1997/98) have poor precision (CVs $=0.59-0.91)$. The WG estimates of relative abundance, in contrast, have better precision $(\mathrm{CVs}=0.19-0.2)$, but cover only three consecutive years, which is a short period of time to accurately estimate trends in abundance. The removal of the observed growth rate did not result in significant changes in the posterior medians, but it did result in greater uncertainty. Loss of precision occurred because the observed growth rate was informative for the estimation of the maximum intrinsic growth rate despite its relatively large CV (0.48).

Uncertainty in catch allocation in the feeding grounds was tested using four catch allocation scenarios. The use of Core (Base Case), Fringe and Falkland Catches allocation scenarios resulted in similar posterior distributions for model parameters and other quantities of interest. This resulted because the catch series among these scenarios were similar. Only 600 more catches were included in the Fringe hypothesis, a difference of less than $2 \%$ relative to Core. These catches originated in the Fringe area between BSA and BSB in the central south Atlantic, where not many humpback whales were taken historically. In addition, only 219 more whales were taken in the Falkland Islands relative to Core. Only the use of the Overlap allocation hypothesis resulted in substantial differences in the posterior distribution of model parameters. These differences were a result of the much lower (nearly 4,000 less) catch allocated to BSA under the Overlap relative to the Core hypothesis. The posterior median of $K$ was nearly $20 \%$ lower and, consequently, the status parameters were more optimistic than the Base Case scenario. The Overlap scenario assumed that $10 \%$ of the catches corresponded to whales caught in the feeding grounds associated with BSG and another $10 \%$ in the feeding grounds associated to BSB. Because catches in these feeding grounds were much lower (nearly 15,000 and 5,000 whales, respectively) than those from BSA (over 29,000 whales), the resulting total catch series under the Overlap hypothesis is lower. Contemporary information from photo-identification, genetic and satellite telemetry data do not support an overlap of whales from Brazil with the feeding grounds associated with BSG (the Antarctic Peninsula) (Dalla Rosa et al., 2008; Olavarria et al., 2000; Rosenbaum et al., 2000; Stevick et al., 2004; Stevick et al., 2006; Zerbini et al., 2006; 2011). Therefore it is possible that the overlap between whales from the two wintering grounds may not be realistic, indicating that results obtained with the Overlap scenario should be viewed with caution.

There was great uncertainty in estimating $r_{\max }$, across all sensitivity scenarios. This is illustrated by the relatively broad shape of the posterior probability distribution of this parameter (Figs 1A, 3A and 4A). However, the posterior distribution does indicate that $r_{\max }$ for the humpback whale BSA is on the higher end of possible values. The posterior median ranged from $6.2-7.5 \% /$ year and there was high probability that it falls between $6-10 \% /$ year. These results are consistent with other estimates of the maximum net recruitment rate of humpback whales in both the Northern and Southern Hemispheres. For example, Stevick et al. (2003) fit a generalised logistic model to a time series of abundance estimates of humpback whales in the North Atlantic and estimated that $r_{\max }$ was $0.078(8.1 \% /$ year $)$ and 

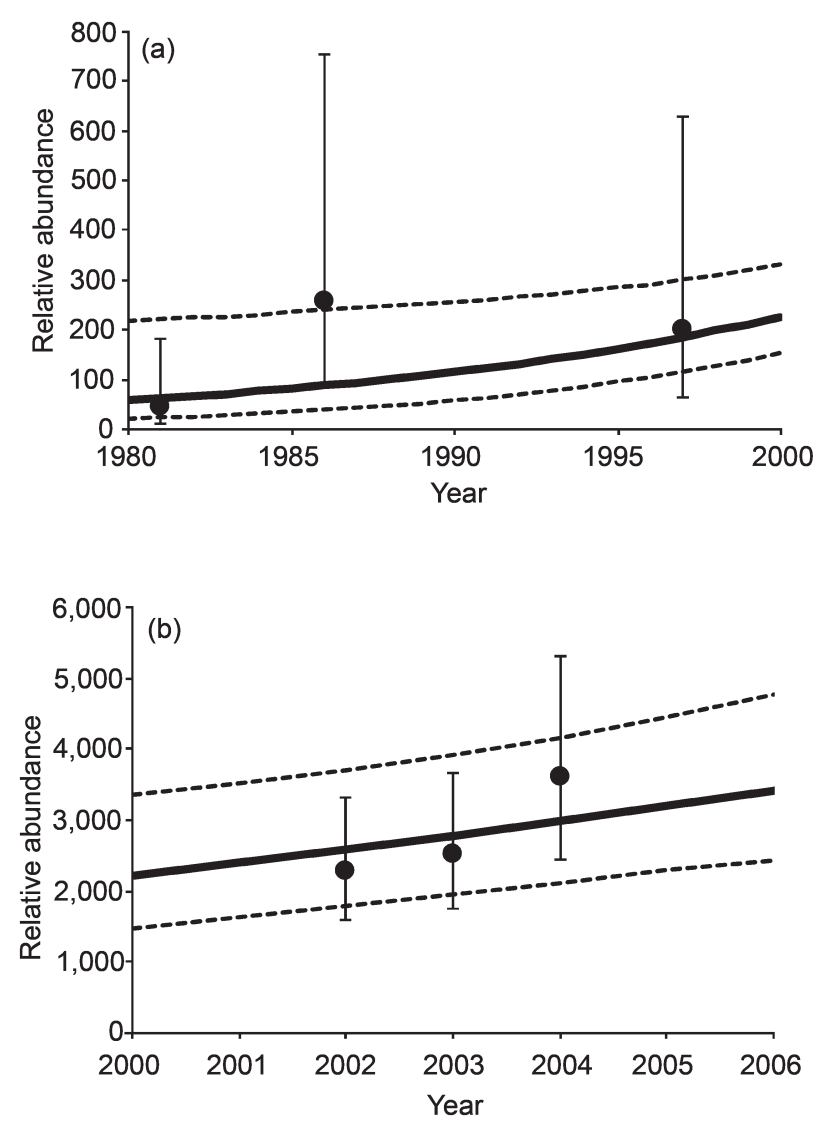

Fig. 5. Fit of the model to the indices of relative abundance in the feeding grounds (A, FGIA scenario) and wintering grounds (B, WGIA scenario). Solid lines correspond to the posterior median, dashed lines to the $95 \%$ probability intervals and error bars to the $95 \%$ confidence intervals of individual relative abundance estimates.

Johnston et al. (2011) have estimated that the $r_{\text {max }}$ posterior medians for the Southern Hemisphere humpback whale stock wintering off the western South American coast (BSG) ranged from 6-7\%/year, depending on the modeling scenario considered.

The models predicted that if no human-induced mortality occurs, BSA should be near $60 \%$ of $K$ within the next 15 years and should be nearly recovered by 2040 . However, predictions of the population status in the future are highly uncertain as revealed by their wide probability intervals. In addition, these predictions are likely unrealistic because this population has been subject to non-natural mortality due to incidental catches in fishing nets, habitat degradation, and possibly to the development of the oil and gas industry in part of the species habitat (e.g. Engel et al., 2004; Siciliano, 1987; Zerbini and Kotas, 1998). Current levels of humaninduced mortality are not known and therefore it is difficult to predict what impact they might have in the recovery of this population. However, if population parameters such as reproductive rates and/or survival are reduced due to anthropogenic factors, a longer period will be required before this stock reaches carrying capacity.

The catch data had the highest impact on the estimate of $K$ and therefore misallocation of catches or underreporting should cause bias in the estimate of the status parameters. Zerbini (2004) showed that an increase (as an example to simulate for missing catches) or a reduction (another example to simulate for misallocation) of $20 \%$ in the catches, resulted, respectively, in an increase or decrease in nearly $20 \%$ in the estimated posterior median of $K$. This positive correlation between the total catch and the estimate of $K$ is also clearly visible in this study (e.g. by comparing results obtained for the Core and Overlap models). Underreporting of catches is likely an issue for the WSA humpback whale population. For example, the coastal whaling station in Costinha, northeastern Brazil, operated from 1910 to 1915 , closed from 1915 to 1923, and operated again from 1924 to 1985 (da Rocha, 1983; Williamson, 1975), but catches were not reported in 1910 and between 1929 and 1946. Because humpbacks whales were the only species taken previously to this period and were regularly taken in subsequent years it is very likely that they were also taken during the period for which catches are missing. Underreporting of catches will cause an upward bias in the estimate of the current status. The magnitude of the bias is unknown as its estimation depends on the number of whales killed but not reported. However, because catches off Brazil have consistently been low (less than 400 individuals in any given year (Williamson, 1975)) and because the 1929-1946 catches from Costinha correspond to a period in which the population had already been severely depleted (Findlay, 2001), it is possible a small number of catches is missing.

The BC estimated that the WSA humpback whale population is at $27 \%$ of its pre-exploitation population size, but the actual status of this population is possibly some unknown number lower than this figure. In addition, for the purpose of the analyses presented here, it is assumed that the population was at carrying capacity before catches were taken in the early 1900s. However, humpback whales were likely caught off the coast of Brazil since at least the 17th century (Ellis, 1969; Lodi, 1992; Smith et al., 2006). The catch history is not known because records were not kept. However, Lodi (1992) indicated that around 50 whales were taken every year. If catches were indeed of this magnitude, it is likely that population was close but not quite at $K$ at the beginning of modern whaling.

The present study provides the first assessment of the humpback whale population wintering off Brazil. This analysis was relatively straightforward, mainly as a consequence of data limitation. For example, the model used is a relatively simple population dynamics model. Alternative models (e.g. age-structured) applied in the assessment of other whale species (e.g. bowhead whales [Brandon et al., 2007; Punt and Butterworth, 1999] and gray whales [Wade, 2002]) could not be used in this study because life-history parameters (e.g. survival, fecundity) and age structure of the catches are not available for the population wintering off Brazil. Lack of other proposed models precludes an assessment of the impact of model uncertainty in this analysis. In addition, it is important to note that additional sources of uncertainty were not included in the analysis. For example, the variances associated to the likelihood equations are assumed to be known, resulting in posterior distributions with lighter tails than would be obtained if these parameters were also estimated (e.g. were given prior distributions). In addition, the population dynamic model ignores process variation and assumes a deterministic trajectory of population size, precluding the use of the true-likelihoods as described in de Valpine (2002). This author showed examples for which the use the true likelihoods improves maximum likelihood estimation over procedures that ignore process noise. The impact of omitting these other sources of uncertainty in the Bayesian inference presented here will be dependent on the balance of information between the priors and the data and should be further investigated in assessment models of 

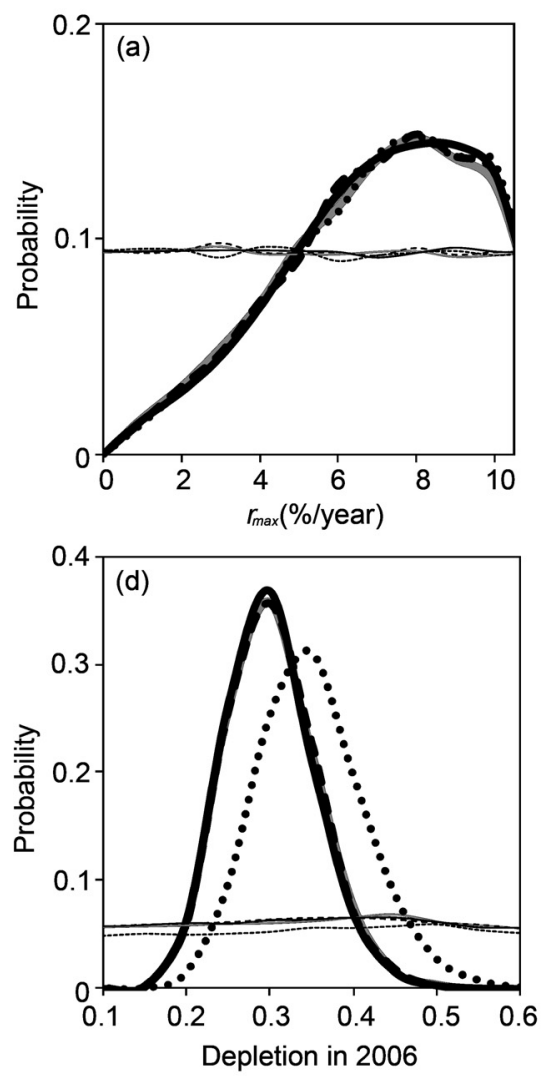
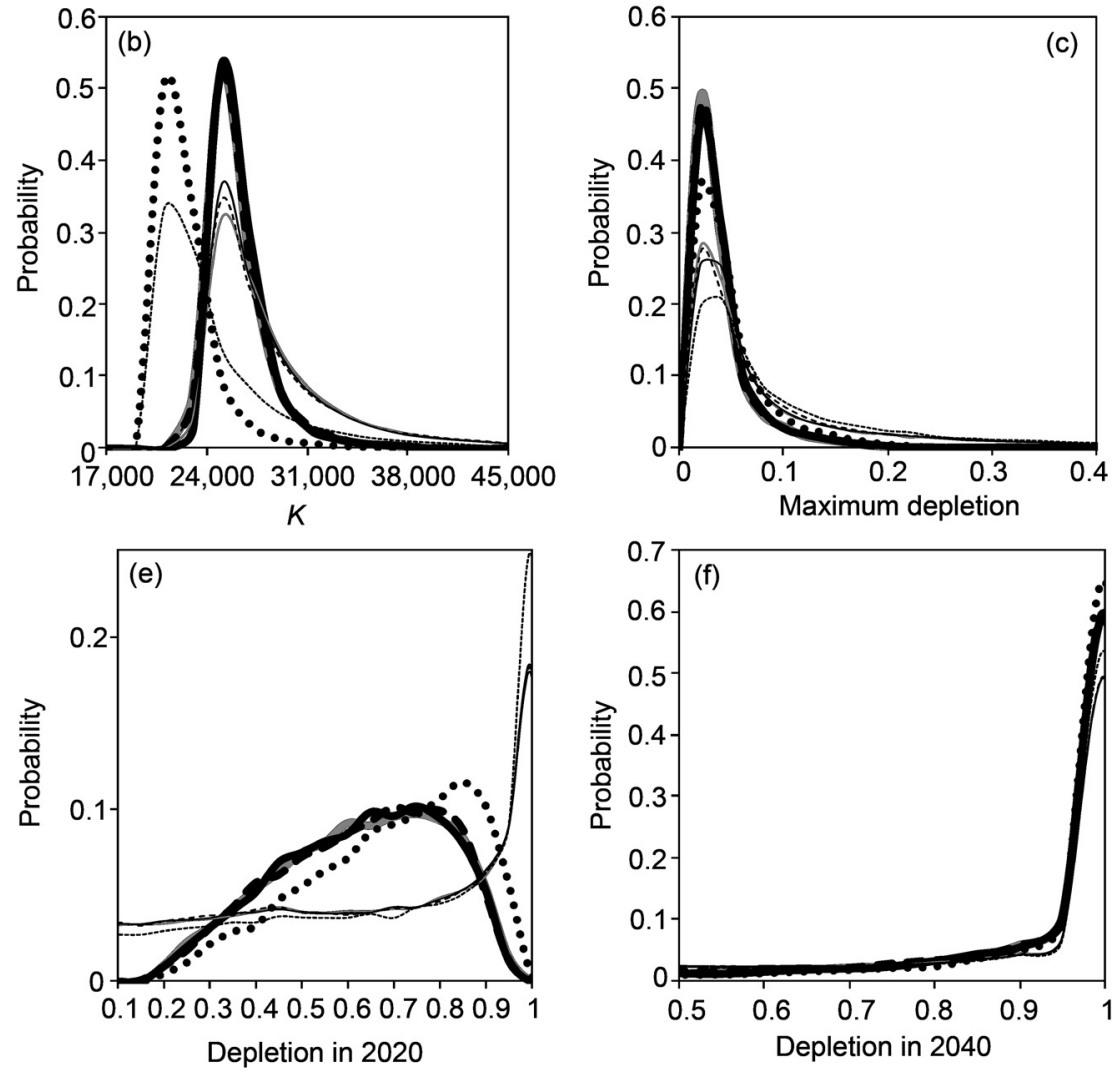

Fig. 6. Posterior (thick lines) and realised prior (thin lines) probability distributions of model parameters and other quantities of interest for the 'Catch Allocation' sensitivity analyses (solid lines $=$ Falkland catches, dashed lines $=$ Fringe hypothesis; dotted line $=$ Overlap hypothesis). The posterior and prior distributions for the base case scenario are illustrated in gray for comparison.

humpback whales. This should be made in conjunction with improvements of the present assessment as more data become available.

\section{CONCLUSION}

Despite the uncertainty in estimating $r_{\max }$, estimates of $K$ and the status parameters were relatively robust across most scenarios presented in this assessment. Results show high posterior probabilities that:

(1) $K$ is within 22,000-28,000 whales;

(2) The population was depleted to less than $4 \%$ of its preexploitation size in the late 1950s;

(3) The current abundance is between 26 and $32 \%$ of $K$.

The results were encouraging as they showed that the humpback whale population in the west South Atlantic has been recovering during the past three decades, after being dramatically reduced by whaling in the early 1900s. However, potential underreporting of catches may have resulted in optimistic estimates of depletion levels. The current estimates indicate that this population is still low relative to historical levels and therefore it requires continued conservation efforts.

\section{ACKNOWLEDGEMENTS}

Ideas, suggestions and assistance with the analysis were provided by Carlos Alvarez, Amanda Bradford, Trevor Branch, John Brandon, Jeff Breiwick, Doug Butterworth, Jason Cope, Doug Kinzey, Ray Hilborn, Andre Punt, Alex Silva, Ian Taylor, Juan Valero and Paul Wade. Trevor Branch also provided code for setting up early versions of the model.
Vera Agostini, Kristin Laidre, André Punt and one anonymous reviewer provided suggestions and comments that greatly improved the manuscript. Alex Zerbini has been funded by the Brazilian Council for Scientific and Technological Development (CNPq, grant No.200285/98-0), the Cetacean Ecology and Assessment Program, National Marine Mammal Laboratory, AFSC/NMFS/NOAA and the School of Aquatic and Fishery Sciences, University of Washington. The Instituto Baleia Jubarte is supported by Petróleo Brasileiro S.A (PETROBRAS) and Aracruz Celulose S.A.

\section{REFERENCES}

Allison, C. 2006. Documentation of the creation of the Southern Hemisphere humpback catch series, February 2006, Cambridge, UK. Paper SC/A06/HW47 presented to the IWC Workshop on Comprehensive Assessment of Southern Hemisphere Humpback Whales, Hobart, Tasmania, 3-7 April 2006 (unpublished). 9pp. [Paper available from the Office of this Journal].

Andriolo, A., Kinas, P.G., Engel, M.H. and Albuquerque Martins, C.C. 2006a. Monitoring humpback whale (Megaptera novaeangliae) population in the Brazilian breeding ground, 2002-2005. Paper SC/58/SH15 presented to the IWC Scientific Committee, May 2006, St. Kitts and Nevis, West Indies (unpublished). 12pp. [Paper available from the Office of this Journal]

Andriolo, A., Martins, C.C.A., Engel, M.H., Pizzorno, J.L., Mas-Rosa, S., Freitas, A.C., Morete, M.E. and Kinas, P.G. 2006b. The first aerial survey to estimate abundance of humpback whales (Megaptera novaeangliae) in the breeding ground off Brazil (Breeding Stock A). J. Cetacean Res. Manage. 8(3): 307-11.

Baker, C.S. and Clapham, P.J. 2004. Modelling the past and future of whales and whaling. Trends Ecol. Evol. 19(7): 365-71.

Best, P.B. 1994. A review of the catch statistics for modern whaling in southern Africa, 1908-1930. Rep. int. Whal. Commn 44: 467-85.

Branch, T.A. 2011. Humpback whale abundance south of $60^{\circ} \mathrm{S}$ from three complete circumpolar sets of surveys. J. Cetacean Res. Manage. (special issue 3): 71-73. 
Branch, T.A. and Butterworth, D.S. 2001. Estimates of abundance south of $60^{\circ} \mathrm{S}$ for cetacean species sighted frequently on the $1978 / 79$ to $1997 / 98$ IWC/IDCR-SOWER sighting surveys. J. Cetacean Res. Manage. 3(3): 251-70.

Branch, T.A., Matsuoka, K. and Miyashita, T. 2004. Evidence for increases in Antarctic blue whales based on Bayesian modelling. Mar. Mammal Sci. 20(4): 726-54.

Butterworth, D.S. and Best, P.B. 1994. The origins of the choice of $54 \%$ of carrying capacity as the protection level for baleen whale stocks, and the implications thereof for management procedures. Rep. int. Whal. Commn 44: 491-97.

Butterworth, D.S. and Punt, A.E. 1995. On the Bayesian approach suggested for the assessment of the Bering-Chukchi-Beaufort Seas stock of bowhead whales. Rep. int. Whal. Commn 45: 303-11.

Clapham, P., Wade, P. and Zerbini, A. 2006. Plausible rates of population growth in humpback whales revisited. Paper SC/58/SH4 presented to the IWC Scientific Committee, May 2006, St. Kitts and Nevis, West Indies (unpublished). 12pp. [Paper available from the Office of this Journal].

da Rocha, J.M. 1983. Revision of Brazilian whaling data. Rep. int. Whal. Commn 33: 419-27.

Dalla Rosa, L., Secchi, E., Maia, Y.G., Zerbini, A. and Heide-Jørgensen, M.P. 2008. Movements of satellite-monitored humpback whales on their feeding ground along the Antarctic Peninsula. Polar Biol. 31: 771-81.

de Valpine, P. 2002. Review of methods for time-series models with process and observation error and likelihood calculations for non-linear, nongaussian state-space models. Bull. Mar. Sci. 70(2): 455-71.

Ellis, M.E. 1969. A caca a baleia no Brasil colonial. Editora Melhoramentos, Sao Paulo.

Engel, M.H., Marcondes, M.C.C., Martins, C.C.A., O’Luna, F., Lima, R.P. and Campos, A. 2004. Are seismic surveys responsible for cetacean's strandings? An unusual mortality of adult humpback whales in Abrolhos Bank, northeast coast of Brazil. Paper SC/56/E28 presented to the IWC Scientific Committee, July 2004, Sorrento, Italy (unpublished). 8pp. [Paper available from the Office of this Journal].

Findlay, K.P. 2001. A review of humpback whale catches by modern whaling operations in the Southern Hemisphere. Mem. Queensl. Mus. 47(2): 411-20.

Findlay, K. and Johnston, S. 2001. Report of the Scientific Committee. Annex G. Report of the Sub-Committee on the Comprehensive Assessment of Whale Stocks - In-depth Assessments. Appendix 3. Further steps towards a preliminary assessment of Southern Hemisphere humpback whales (breeding stocks A and G). J. Cetacean Res. Manage. (Suppl.) 3: 193-94.

Findlay, K.P., Cunningham, C.L. and Butterworth, D.S. 2000. A first step towards a preliminary assessment of Southern Hemisphere humpback whales. Paper SC/52/IA5 presented to the IWC Scientific Committee, June 2000, in Adelaide, Australia (unpublished). 23pp. [Paper available from the Office of this Journal].

Freitas, A.C., Kinas, P.G., Martins, C.A.C. and Engel, M.H. 2004 Abundance of humpback whales on the Abrolhos Bank wintering ground, Brazil. J. Cetacean Res. Manage. 6(3): 225-30.

Furtado-Neto, M.A.A., Monteiro-Neto, C., Campos, A.A., Lien, J. and Carr, S. 1998. Are Northern-Hemisphere humpback whales stranding in South Atlantic beaches? Answers from mitochondrial DNA sequences. Abstracts of the $8^{\circ}$ Reunião de Trabalhos de Especialistas em Mamíferos Aquáticos da América do Sul e $2^{\circ}$ Congresso da Sociedade Latino Americana de Mamíferos Aquáticos - SOLAMAC. p.89. [In Portuguese].

Gambell, R. 1973. How whales survive. pp.193-202. In: Calder, N. (eds). Nature in the Round. Weidenfeld and Nicolson, London.

Gelman, A., Carlin, B.P., Stern, H.S. and Rubin, D.B. 1995. Bayesian Data Analysis, 2nd Edition. Chapman and Hall/CRC, Boca Raton, FL, USA, London. 668pp.

International Whaling Commission. 1998. Report of the Scientific Committee. Rep. int. Whal. Commn 48:53-118.

International Whaling Commission. 2005. Report of the Scientific Committee. Annex H. Report of the sub-committee on other Southern Hemisphere whale stocks. J. Cetacean Res. Manage. (Suppl.) 7:235-44.

International Whaling Commission. 2006. Report of the Scientific Committee. Annex H. Report of the Sub-Committee on the Other Southern Hemisphere Whale Stocks. J. Cetacean Res. Manage. (Suppl.) 8:151-70.

International Whaling Commission. 2007. Report of the Scientific Committee. Annex H. Report of the Sub-Committee on Other Southern Hemisphere Whale Stocks. J. Cetacean Res. Manage. (Suppl.) 9:188209.

International Whaling Commission. 2011. Report of the Workshop on the Comprehensive Assessment of Southern Hemisphere humpback whales, Hobart, Tasmania, 4-7 April 2006. J. Cetacean Res. Manage.(special issue 3): 1-50.

Jackson, J.A., Zerbini, A., Clapham, P., Garrigue, C., Hauser, N., Poole, M. and Baker, C.S. 2006. A Bayesian assessment of humpback whales on breeding grounds of eastern Australia and Oceania (IWC Stocks E, E1, E2 and F). Paper SC/A06/HW52 presented to the IWC Workshop on Comprehensive Assessment of Southern Hemisphere Humpback Whales, Hobart, Tasmania, 3-7 April 2006 (unpublished). 19pp. [Paper available from the Office of this Journal].

Johnston, S.E., Zerbini, A.N. and Butterworth, D.S. 2011. A Bayesian approach to assess the status of Southern Hemisphere humpback whales (Megaptera novaeangliae) with an application to Breeding Stock G. Journal of Cetacean Research and Management (special issue 3): 309-317.

Johnston, S.J. and Butterworth, D.S. 2004. Updated age-aggregated production modelling assessments of the Southern Hemisphere humpback whale breeding stocks A and C. Paper SC/56/SH20 presented to the IWC Scientific Committee, July 2004, Sorrento, Italy (unpublished). 20pp. [Paper available from the Office of this Journal].

Johnston, S.J., Butterworth, D.S. and Findlay, K.P. 2001. Further results from a preliminary assessment of Southern Hemisphere humpback whales. Paper SC/53/IA20 presented to the IWC Scientific Committee, July 2001, London (unpublished). 31pp. [Available from the Office of this Journal]

Kinas, P.G. and Bethlem, C.B.P. 1998. Empirical Bayes abundance estimation of a closed population using mark-recapture data, with application to humpback whales, Megaptera novaeangliae, in Abrolhos, Brazil. Rep. int. Whal. Commn 48: 447-50.

Lodi, L. 1992. Uma história da caça á baleia. Ciência Hoje 14(81): 78-83. [In Portuguese].

Lodi, L. 1994. Ocorrências de baleias-jubarte, Megaptera novaeangliae, no Arquipélago de Fernando de Noronha, incluindo um resumo de registros de capturas no Nordeste do Brasil. Biotemas 7(1,2): 116-23. [In Portuguese].

Martins, C.C.A., Morete, M.E., Engel, M.H., Freitas, A.C., Secchi, E.R. and Kinas, P.G. 2001. Aspects of habitat use patterns of humpback whales in the Abrolhos Bank, Brazil, breeding ground. Mem. Queensl. Mus. 47(2): 563-70.

McAllister, M.K., Pikitch, E.K., Punt, A.E. and Hilborn, R. 1994. A Bayesian approach to stock assessment and harvest decisions using the sampling/importance resampling algorithm. Can. J. Fish. Aquat. Sci. 12: 2673-87.

Nunney, L. 1993. The influence of mating system and overlapping generations on effective population size. Evolution 47: 1329-41.

Olavarria, C., Baker, C.S., Medrano, G.L., Aguayo, L.A., Caballero, S. Florez-Gonzalez, L., Capella, A.J., Rosenbaum, H.C., Garrigue, C., Greaves, J., Bannister, J.L., Jenner, M. and Jenner, C. 2000. Stock identity of Antarctic Peninsula humpback whales inferred from mtDNA variation. Paper SC/52/IA15 presented to the IWC Scientific Committee, June 2000, Adelaide, Australia (unpublished). 12pp. [Paper available from the Office of this Journal].

Patenaude, N.J. 2002. Demographic and genetic status of southern right whales at the Auckland Islands, New Zealand, University of Auckland, Auckland, New Zealand. 241pp.

Pella, J.J. and Tomlinson, P.K. 1969. A generalised stock production model. Inter-American Tropical Tuna Commission Bulletin 13(3): 421-96.

Punt, A.E. and Butterworth, D.S. 1996. Further remarks on the Bayesian approach for assessing the Bering-Chukchi-Beaufort Seas stock of bowhead whales. Rep. int. Whal. Commn 46: 481-91.

Punt, A.E. and Butterworth, D.S. 1999. On assessment of the BeringChukchi-Beaufort Seas stock of bowhead whales (Balaena mysticetus) using a Bayesian approach. J. Cetacean Res. Manage. 1(1): 53-71.

Punt, A.E. and Hilborn, R. 1997. Fisheries stock assessment and decision analysis: A review of the Bayesian approach. Rev. Fish Biol. Fish. 7: 3563.

Reilly, S., Hedley, S., Borberg, J., Hewitt, R., Thiele, D., Watkins, J. and Naganobu, M. 2004. Biomass and energy transfer to baleen whales in the South Atlantic sector of the Antarctic. Deep-Sea Res. II 51: 1397-409.

Roman, J. and Palumbi, S.R. 2003. Whales before whaling in the North Atlantic. Science 301: 508-10.

Rosenbaum, H.C., Best, P.B., Findlay, K.P., Engel, M.H., Pomilla, C., Razafindrakoto, Y., Morete, M.E., Vely, M., Freitas, A.C., Baker, C.S., Jenner, C., Jenner, M.N. and Bannister, J. 2000. Mitochondrial DNA variation among humpback whales from the wintering grounds in the South Atlantic and southwestern Indian Oceans. Paper SC/52/IA11 presented to the IWC Scientific Committee, June 2000, Adelaide, Australia (unpublished). [Paper available from the Office of this Journal].

Rosenbaum, H.C., Pomilla, C.C., Leslie, M.C., Mendez, M.C., Best, P.B., Collins, T., Engel, M.H., Ersts, P.J., Findlay, K.P., Bonatto, S., Kotze, P.G.H., Meyer, M., Minton, G., Barendse, J., Thorton, M., Razafindrakoto, Y. and Ngouessono. 2006. Mitochondrial DNA diversity and population structure of humpback whales from their wintering areas (breeding stocks) in the Indian and South Atlantic Oceans (wintering regions $\mathrm{A}, \mathrm{B}, \mathrm{C}$ and $\mathrm{X}$ ). Paper $\mathrm{SC} / \mathrm{A} 06 / \mathrm{HW} 41$ presented to the IWC 
Workshop on Comprehensive Assessment of Southern Hemisphere Humpback Whales, Hobart, Tasmania, 3-7 April 2006 (unpublished). 16pp. [Paper available from the Office of this Journal].

Siciliano, S. 1987. Nota sobre a captura acidental de Megaptera novaeangliae na costa sudeste do Brasil. p.115. Paper presented at the Anais da 2a Reuniao de Trabalho de Especialistas em Mamíferos Aquáticos de América do Sul, Rio de Janeiro, Brasil. [In Portuguese].

Smith, T.D., Josephson, E. and Reeves, R.R. 2006. 19th century Southern Hemishere humpback whale catches. Paper SC/A06/HW53 presented to the IWC Workshop on Comprehensive Assessment of Southern Hemisphere Humpback Whales, Hobart, Tasmania, 3-7 April 2006 (unpublished). 10pp. [Paper available from the Office of this Journal]

Stevick, P.T., Aguayo, A., Allen, J., Avila, I.C., Capella, J., Castro, C., Chater, K., Dalla Rosa, L., Engel, M.H., Felix, F., Florez-Gonzalez, L., Freitas, A., Haase, B., Llano, M., Lodi, L., Munoz, E., Olavarria, C., Secchi, E., Scheidat, M. and Siciliano, S. 2004. Migrations of individually identified humpback whales between the Antarctic peninsula and South America. J. Cetacean Res. Manage. 6(2): 109-13.

Stevick, P.T., Allen, J., Clapham, P.J., Friday, N., Katona, S.K., Larsen, F., Lien, J., Mattila, D.K., Palsbøll, P.J., Sigurjónsson, J., Smith, T.D., Øien, N. and Hammond, P.S. 2003. North Atlantic humpback whale abundance four decades after protection from whaling. Marine Ecology. Progress Series 258: 263-73.

Stevick, P.T., Pacheco de Godoy, L., McOsker, M., Engel, M.H. and Allen, J. 2006. A note on the movement of a humpback whale from Abrolhos Bank, Brazil to South Georgia. J. Cetacean Res. Manage. 8(3): 297-300.

Tønnessen, J.N. and Johnsen, A.O. 1982. The History of Modern Whaling. C. Hurst \& Co., London. i-Xx+798pp.

Wade, P.R. 2002. A Bayesian stock assessment of the eastern Pacific gray whale using abundance and harvest data from 1967-1996. J. Cetacean Res. Manage. 4(1): 85-98.

Walters, C.J. and Ludwig, D. 1994. Calculation of Bayes posterior probability distributions for key population parameters. Can. J. Fish. Aquat. Sci. 51: 713-22.

Ward, E., Zerbini, A.N., Kinas, P.G., Engel, M.H. and Andriolo, A. 2011. Estimates of population growth rates of humpback whales (Megaptera novaeangliae) in the wintering grounds off the coast of Brazil (Breeding
Stock A). Journal of Cetacean Research and Management (special issue 3): $145-149$.

Williamson, G.R. 1975. Minke whales off Brazil. Sci. Rep. Whales Res. Inst., Tokyo 27: 37-59.

Yablokov, A.V., Zemsky, V.A., Mikhalev, Y.A., Tormosov, V.V. and Berzin, A.A. 1998. Data on Soviet whaling in the Antarctic in 1947-1972 (population aspects). Russ. J. Ecol. 29(1): 38-42.

Zemsky, V.A., Berzin, A.A., Mikhalev, Y.A. and Tormosov, D.D. 1996. Soviet Antarctic whaling data (1947-1972). 2nd ed. Center for Russian Environment Policy, Moscow. 336pp. [Unless referring to additional Appendices use Ist Edition - see 1995 reference - this is a "reprint"].

Zerbini, A.N. 2004. Status of the Southern Hemisphere humpback whale breeding stock A: preliminary results from a Baysian assessment. Paper SC/56/SH17 presented to the IWC Scientific Committee, July 2004, Sorrento, Italy (unpublished). 18pp. [Paper available from the Office of this Journal].

Zerbini, A.N. 2005. An updated Bayesian assessment of the Southern Hemisphere humpback whale Breeding Stock A. Paper SC/57/SH16 presented to the IWC Scientific Committee, June 2005, Ulsan, Korea (unpublished). 13pp. [Paper available from the Office of this Journal].

Zerbini, A.N., Andriolo, A., Da Rocha, J.M., Simoes-Lopes, P.C., Siciliano, S., Pizzorno, J.L., Waite, J.M., DeMaster, D.P. and VanBlaricom, G.R. 2004. Winter distribution and abundance of humpback whales (Megaptera novaengliae) off northeastern Brazil. J. Cetacean Res. Manage. 6(1): 101-07.

Zerbini, A.N., Andriolo, A., Heide-Jørgensen, M.P., Pizzorno, J.L., Maia, Y.G., VanBlaricom, G.R., DeMaster, D.P., Simões-Lopes, P.C., Moreira, S. and Bethlem, C. 2006. Satellite-monitored movements of humpback whales (Megaptera novaeangliae) in the Southwest Atlantic Ocean. Mar. Ecol. Prog. Ser 313: 295-304.

Zerbini, A.N., Andriolo, A., Heide-Jørgensen, M.P., Moreira, S.C., Pizzorno, J.L., Maia, Y.G., VanBlaricom, G.R. and DeMaster, D.P. 2011. Migration and summer destinations of humpback whales (Megaptera novaeangliae) in the western South Atlantic Ocean. J. Cetacean Res. Manage. (special issue 3): 113-118.

Zerbini, A.N. and Kotas, J.E. 1998. A note on cetacean bycatch in pelagic driftnetting off southern Brazil. Rep. int. Whal. Commn 48: 519-24. 